\title{
Study on Relationship between the National Sharing of Physical Education Facilities in Colleges and Universities and Environmental Pollution
}

\author{
Changshui Cui \\ Xi'an International University; Xi'an 710077 China
}

Keywords: college sports facilities; environmental pollution; ecological civilization; green health.

\begin{abstract}
The implementation of college sports open to the outside world and the sharing of all people can improve the utilization of sports facilities, attract more people to participate in physical exercise, thereby reducing other activities to the environment pollution. To improve the physical fitness of the masses. There is a binding relationship between the national sharing of sports facilities and the improvement of environmental pollution in colleges and universities. The necessity and current situation of national sharing of sports facilities in colleges and universities are analyzed. Combined with the current situation of national fitness under the environment of environmental pollution, more and more people realize the importance of ecological civilization and green environment to health through the implementation of open and universal sharing of physical education in colleges and universities. Therefore, the consciousness of environmental protection is formed consciously, the construction of environmental protection is promoted through sports, the green and healthy life is realized, the emission of environmental pollution is reduced, and the harmonious development of human, nature and society is followed.
\end{abstract}

\section{Introduction}

With the continuous upsurge of the national fitness craze, there is more and more enthusiasm for the opening and sharing the sports facilities in colleges and universities. On August 19, 2009, the state council promulgated the national fitness regulations which went into effect on October 1, 2009. Article 28: "public schools shall actively create conditions to open sports facilities to the public". Since that time, there is a legal basis for the opening of sports facilities in colleges and universities and the sharing of the whole people. College sports facilities are well equipped with abundant sports equipment resources. According to the fifth sports ground survey gazette, there are 850080 sports facilities in China now while 558044 of them are belong to the education system. School sports facilities account for 65.6 percent of the country's sports venues, but only 29.2 percent of them are open to society. There is still a certain gap between the public sharing and openness of sports facilities in colleges and universities and the demand of society [1].

With the enhancement of green ecological construction and public awareness of environmental protection, people pay more and more attention to the environmental quality of sports. Share the college sports facilities, can cultivate people's sports enthusiasm, make the people pay more attention to the cultivation of the consciousness of environmental protection, pay more attention to environmental pollution damage on the environment movement, get into the habit of good care environment and attach importance to environmental pollution [2] Therefore, the sharing of sports facilities in colleges and universities is closely related to environmental pollution control. Through the sharing of sports facilities, there are positive social and economic benefits in promoting environmental pollution control and improving the physical quality of the people. Taking physical exercise in the beautiful and green environment in the university, people will aware the importance of green environment construction better and form environmental awareness and green ecological civilization concept. Taking physical exercise in the green ecological environment will promote the harmonious coexistence between people, people and nature, people and society. 


\section{The Utilization Status of Sports Facilities in Colleges and Universities}

With the improvement of people's living standards and the increasing importance of health care, the national fitness craze is running high. However, China's sports facilities resources are still relatively scarce, the environmental pollution is serious, and the construction of green space park lags. Neither the environmental quality nor the sports facilities can effectively meet the needs of people's fitness. As a well-equipped place for sports facilities, colleges and universities have abundant sports facilities resources. However, due to the closed nature of the university's environment and safety problems, the degree of openness of sports facilities in colleges and universities is not enough, and there is a certain gap between the goal of the universal sharing of sports facilities in colleges and universities [3]. With the appeal of relevant people and the rising voices of the people, the relevant measures for the sharing and opening of sports facilities in colleges and universities are under way. Relevant professionals pointed out that "We should establish a set of rules about opening school sports facilities to public, such as, business license registration, tax and charge license, purchase invoice guidance, to share sports facilities in colleges and universities in a better way." Under the appeal of the people, the public sharing of sports facilities in colleges and universities is gradually advancing. According to the statistical analysis, the proportion of university sports facilities opening in the past ten years is shown in figure 1.

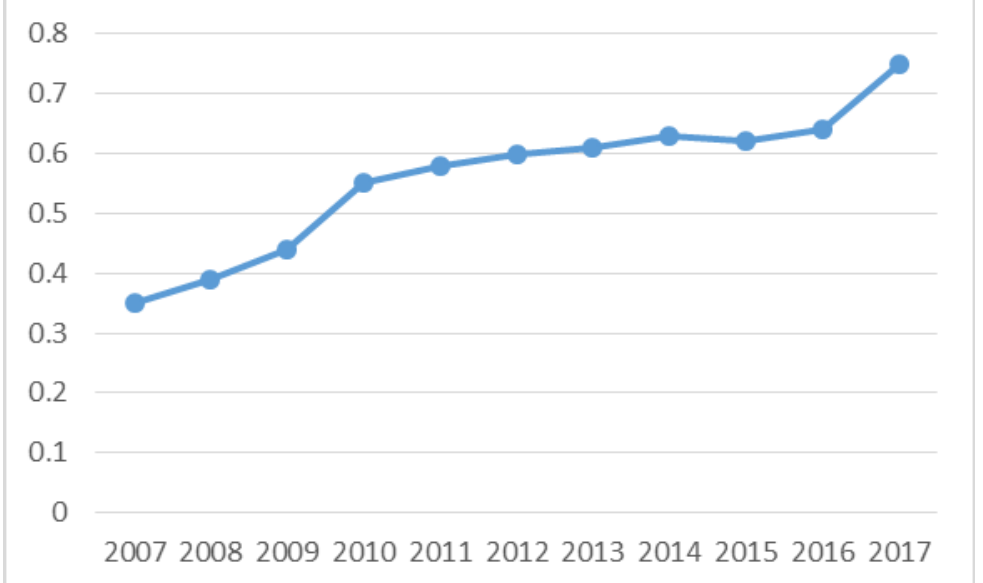

Fig 1. proportion of college sports opening scale.

Statistical analysis shows, in the joint efforts of various departments, colleges and universities sports facilities the sharing degree is gradually increased, the sports facilities of opening ratio gradually increased each year to meet the needs of the people of physical exercise and fitness. But due to the management of college sports facilities system is not perfect enough, we still need to refine the related work, improve the level of the sharing of college sports facilities, to improve the efficiency of resource using and avoid the waste of college sports facilities resources. Only in this way, we can encourage more people to join in the sports fitness, promote the formation of green ecological environmental protection consciousness, constructe our home in green environment, realize the energy conservation and emissions reduction, reduce the pollution of the environment and promote the construction of green ecological (4-6).

\section{The Positive Role of the Public Sharing of Sports Facilities in Colleges and Universities}

Problems such as unreasonable resource utilization and low open extent, which waste the sport resources, are still exist in sharing of sports resources in colleges. This is not conducive to environmental protection and the construction of a conservation-minded society. According to the survey, the general utilization rate of college sports venues is less than one third of the total utilization rate of national sports venues. The daily maintenance cost of sports facilities is high and the utilization rate is low, which leads to environmental pollution and waste of sports resources. Therefore, how to effectively use of college sports resources and improve resource utilization become an important direction in the research of ecological environmental construction. Promoting the 
sharing of college sports facilities is of great significance to reduce the pollution of the environment [7].

(1) Sharing of sports facilities in colleges and universities can realize the optimal allocation of sports facilities, physical education courses and sports talents. In cities with large population density, open University sports resources can reduce people's travel distance, thus reduce the possibility of emission pollution and provide convenience for people. Optimizing the sharing level of sports facilities in colleges and universities, citizens can choose colleges and universities for physical exercise according to their own needs and interests, thus greatly reducing carbon emissions and pollution emissions. According to the survey, through the sharing of sports facilities in colleges and universities, the proportion distribution of carbon emissions is shown in figure 2. The sharing of sports facilities enhances the utilization of sports facilities, enlarges the socialization degree of sports resources, and can effectively reduce carbon emission, thus reducing environmental pollution.

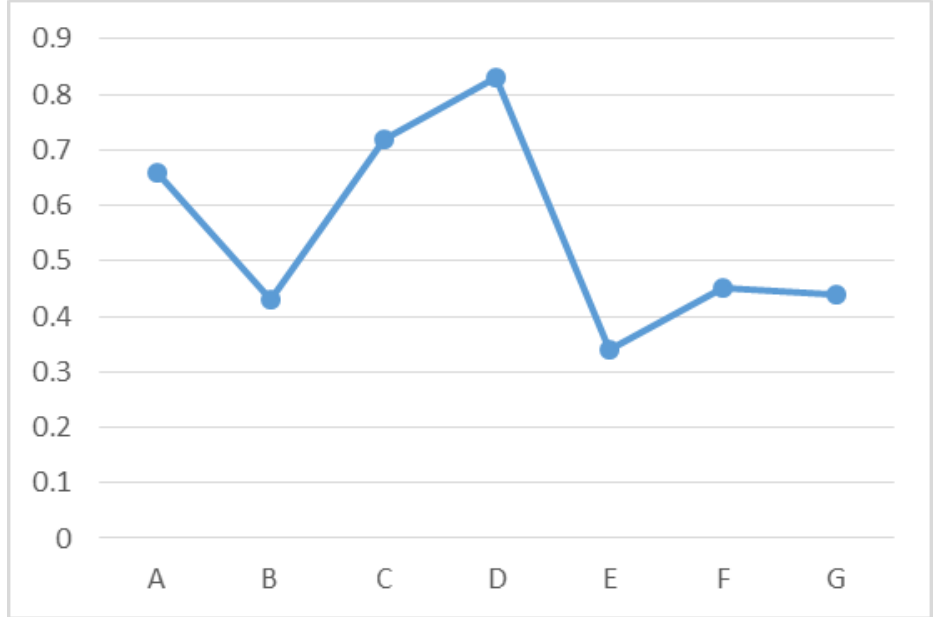

Fig 2. the proportion of carbon emission of each monitoring point after the university sports facilities are Shared.

(2) The universal sharing of sports facilities in colleges and universities plays an important role in the construction of a harmonious society and the construction of ecological civilization. College sports resources are relatively rich, through sharing with the public in the sports and fitness exercise, it can further cultivate the awareness of ecological civilization, foster everyone love environment and the consciousness of protecting the environment, make people more appreciative of the green ecological environment, give urban citizens greener environment by enhancing environmental pollution treatment. So, we can improve the environment while improving the physical quality.

(3) The sharing of sports facilities in universities can further adjust the energy consumption structure of cities. Through regular supervision and monitoring of environmental pollution by creating standardized management system, we can enhance people's environmental protection consciousness, improve the actual situation of physical training, set up the mechanism of environmental protection, reduce environmental pollution, green environmental regulation can enhance environmental protection supervision in social ability, promote the construction of ecological civilization, according to the degree of social sports resources sharing in control the environmental pollution.

\section{The Promotion and Correlation Analysis of Positive Effect of the Sharing of College Sports Facilities in Environmental Protection}

There is a binding relationship between the public sharing of sports facilities in universities and the improvement of environmental pollution. The author adopts the statistical analysis and correlation statistical analysis method to establish the correlation model between the public sharing of sports facilities in universities and the environmental pollution control. The descriptive statistical characteristics of the degree of sharing of sports facilities in colleges and universities mainly include the opening degree of sports facilities, the distribution scale of sports facilities and the scale of sports 
facilities, etc. [8-10]. Combined with different sports facilities for the promotion of health and the environment pollution of governance, we get descriptive statistical results with correlation index and promote factor for different sports facilities and the environment pollution, are shown in table 1.

Table 1. descriptive statistical results of the correlation index and promotion factor of sports facilities on environmental pollution control.

\begin{tabular}{|c|c|c|}
\hline Project & correlation index & promote factor \\
\hline Basketball court & 0.353 & 5.245 \\
\hline Football field & 0.821 & 4.323 \\
\hline badminton court & 0.242 & 3.543 \\
\hline Indoor aerobics & 0.276 & 8.213 \\
\hline Table Tennis & 0.665 & 6.754 \\
\hline Fitness equipment & 0.533 & 5.943 \\
\hline Swimming pool & 0.455 & 6.213 \\
\hline Tennis court & 0.268 & 6.23 \\
\hline
\end{tabular}

The descriptive statistics results show that, the sharing of college sports facilities has significant correlation level with environmental pollution. Through establishing the sharing and distribution model of college sports facilities, we can find that physical exercise is beneficial to cultivate people's ecological civilization consciousness and reduce waste discharge. Based on the regression analysis method, the correlation index distribution of the contribution of university sports facilities to environmental pollution control is shown in Figure 3.

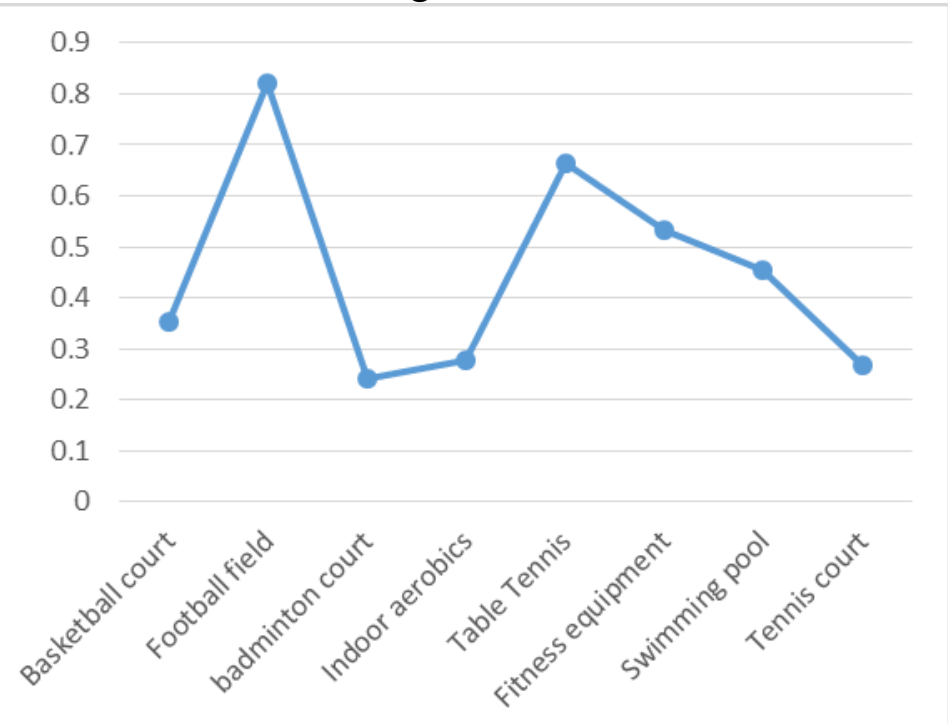

Fig 3. correlation index distribution of the contribution of university sports facilities to environmental pollution control.

The statistical analysis results of the promotion of environmental ecological civilization construction are shown in figure 4 . The analysis shows that, through the sharing of sports facilities in colleges and universities, the average level of promotion of environmental protection is $34 \%, 23.4 \%$ and $42.8 \%$, respectively. Sharing of college sports facilities can guide people from indoor to sports stadium, to get in touch with nature, feel the nature, develop green ecological view, reduce environmental pollution, promote the construction of ecological civilization, promote people exercise through the green travel way of life, thus the formation of environmental protection consciousness, through the sports to promote the environmental construction, realizes the green and healthy life, reduce environmental pollution. 
Thus, sharing of college sports facilities and there is close related between environmental pollution. The improvement of the college sports facilities open degree is conductive to enhancing the national fitness enthusiasm, enable people to develop low carbon environmental protection way of life, to cultivate green concept of life, thus reducing environmental pollution emissions, improve the level of environmental governance.

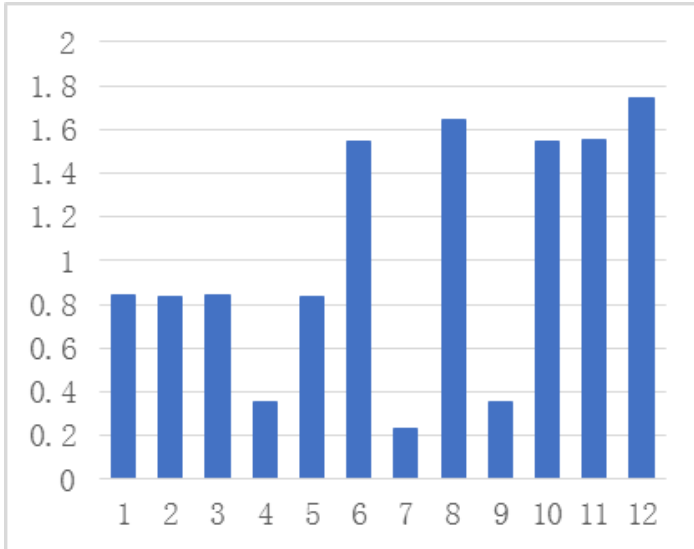

Fig 4. statistical analysis on the promotion of environmental ecological civilization construction.

\section{Conclusion}

The sharing of sports facilities in colleges and universities is related to improving environmental pollution. The utilization of sports resources and sports venues in colleges and universities still has some problems such as unreasonable utilization of resources and insufficient degree of openness. This has resulted in a great deal of waste of resources, which is not conducive to environmental protection and the construction of resource-conserving society. The sharing of sports facilities in colleges and universities can promote people's awareness of green environmental protection which loves sports and sports. This can cultivate green travel and low carbon environmental protection. More and more people realize the importance of ecological civilization and green environment to physical health. Therefore, it could develop environmental awareness, promote ecological and healthy development, and promote harmonious coexistence between human and nature.

\section{Acknowledgements}

Project: General subjects of Shaanxi Sports Bureau in 2017: "Project Name: survey on the satisfaction degree of sports facilities in Shaanxi province" (17119).

\section{References}

[1]. Zheng Daoyang, Li Xinjie, He Fenglan, etc. Investigation on the status quo of the ecological civilization construction of the walking tour routes around Guilin -- taking Lingchuan county as an example [J]. China science and technology,2015 (16) :12-13.

[2]. RAO C S, REDDY K C, RAO D S. Power control technique for efficient call admission control in advanced Wireless Networks[J]. International Journal on Computer Science and Engineering,2012,4(6):962-973.

[3]. Shi Hai-Yan,Wang Wan-Liang, KWOKNM, et al. Game theory for Wireless Sensor Networks: a survey[J].Sensors,2012,12(7):9055-9097.

[4]. TUSHAR W, SMITH D, LAMAHEWATA, et al Non-cooperative power control game in A multi-source wireless sensor network[C]//Communications Theory Workshop (AusCTW), Australian,2012:43-48. 
[5]. Wang Feng. Analysis on the impact of intelligent building on environmental energy conservation and emission reduction [J]. Environmental science and management, 2014,42(11):59-62.

[6]. Zhang Qiji, Zhu Mengjie, Liu Ning. Evaluation of Anhui circular economy development based on analytic hierarchy process [J]. Environmental science and management, 2014,42(11): $170-173$.

[7]. STANKOVIC M S, JOHANSSON K H, STIPANOVIC D, M. Distributed seeking of Nash, Bria with applications to mobile sensor networks[J]. IEEE Transaction on Automatic Control,2012,57(4):904-919.

[8]. FRIHAUF P, KRSTIC M, BASAR T. Nash equilibrium seeking in Noncooperative games[J]. IEEE Transaction on Automatic Control,2012,57(5):1192-1207.

[9]. Yellow River. Application of happy PE teaching in vocational sports teaching [J]. Education,2015,46(12):197.

[10]. Wang Yu expansion, Chen Qinglin, Li Huizeng. Research on the reform and development of physical education curriculum in vocational colleges [J]. Journal of Beijing sports university,2005, 7: 960-961. 